\title{
Human exposure to arsenic from drinking water in Vietnam
}

Tetsuro Agusa ${ }^{1, *}$, Pham Thi Kim Trang ${ }^{2}$, Vi Mai Lan ${ }^{2}$, Shinsuke Tanabe ${ }^{1}$, Pham Hung Viet ${ }^{2}$,

Michael Berg ${ }^{3}$

${ }^{1}$ Center for Marine Environmental Studies (CMES), Ehime University, Bunkyo-cho 2-5,

Matsuyama 790-8577, Japan

${ }^{2}$ Center for Environmental Technology and Sustainable Development (CETASD), Hanoi

University of Science, 334 Nguyen Trai, Hanoi, Vietnam

3 Eawag, Swiss Federal Institute of Aquatic Science and Technology, 8600 Dübendorf, Switzerland

* Corresponding author

E-mail: ax@agr.ehime-u.ac.jp

Key words

Arsenic, Health, Groundwater, Speciation, Hair, Urine, Removal, Sand filter

This document is the accepted manuscript version of the following article:

Agusa, T., Trang, P. T. K., Lan, V. M., Anh, D. H., Tanabe, S., Viet, P. H., \& Berg, M. (2014). Human exposure to arsenic from drinking water in vietnam. Science of the Tota 7 Environment, 488, 562-569. http://doi.org/10.1016/j.scitotenv.2013.10.039

This manuscript version is made available under the CC-BY-NC-ND 4.0 license http://creativecommons.org/licenses/by-nc-nd/4.0/ 


\begin{abstract}
Vietnam is an agricultural country with a population of about 88 million, with some 18 million inhabitants living in the Red River Delta in North Vietnam. The present study reports the chemical analyses of 68 water and 213 biological (human hair and urine) samples conducted to investigate arsenic contamination in tube well water and human arsenic exposure in four districts (Tu Liem, Dan Phuong, Ly Nhan, Hoai Duc) in the Red River Delta. Arsenic concentrations in groundwater in these areas were in the range of $<1$ to $632 \mu \mathrm{g} / \mathrm{L}$, with severe contamination found in the communities Ly Nhan, Hoai Duc, and Dan Phuong. Arsenic concentrations were markedly lowered in water treated with sand filters, except for groundwater from Hoai Duc. Human hair samples had arsenic levels in the range of $0.07-7.51 \mu \mathrm{g} / \mathrm{g}$, and among residents exposed to arsenic levels $\geq 50 \mu \mathrm{g} / \mathrm{L}, 64 \%$ of them had hair arsenic concentrations higher than $1 \mu \mathrm{g} / \mathrm{g}$, which is a level that can cause skin lesions. Urinary arsenic concentrations were $4-435 \mu \mathrm{g} / \mathrm{g}$ creatinine.

Concentrations of arsenic in hair and urine increased significantly with increasing arsenic content in drinking water, indicating that drinking water is a significant source of arsenic exposure for these residents. The percentage of inorganic arsenic (IA) in urine decreased with age, whereas the opposite trend was observed for monomethylarsonic acid (MMA) in urine. Significant cointeractions of age and arsenic exposure status were also detected for concentrations of arsenic in hair and the sum of IA, MMA, and dimethylarsinic acid (DMA) in urine and \%MMA. In summary, this study demonstrates that a considerable proportion of the Vietnamese population is exposed to arsenic levels of chronic toxicity, even if sand filters reduce exposure in many households. Health problems caused by arsenic ingestion through drinking water are increasingly reported in Vietnam.
\end{abstract}




\section{Introduction}

Arsenic contamination of drinking water extracted from tube wells has been found over the last twenty years in many countries in the world, but especially in South Asian regions such as Bangladesh and the West Bengal region of India. This is considered one of the most significant natural pollutions in the world, with many millions of people now chronically exposed. Remarkable percentages (10-20\%) of people examined in Bihar (India) and Bangladesh were identified to have typical skin lesions and cancers associated with arsenic exposure (Chakraborti et al., 2003, Chowdhury et al., 2000). Furthermore, other cancers in several organs such as liver, lung, and bladder were observed in people with high arsenic exposure (Rahman et al., 2001). For pregnant women, chronic arsenic exposure has caused excess spontaneous abortion, stillbirth and preterm birth rates (Ahmad et al., 2001; Milton et al., 2005).

Several studies have evaluated biological samples such as hair, urine and nail specimens for the arsenic burden in the human body. Upon exposure, arsenic accumulates in the keratin-rich tissues in the body, especially hair and nails. This is thought to reflect the binding of arsenite (As(III)) to sulfhydryl groups in keratin. Nonexposed hair samples contained $<1 \mu \mathrm{g} / \mathrm{g}$ arsenic (Mahata et al., 2003, Saad and Hassanien, 2001). However, while hair samples are often used as a biomarker for long-term exposure to arsenic, urine samples are more indicative of recent exposure. Both analyses are reliable biomarkers for human body burden to arsenic (Chen et al., 2005, Hughes 2007). Inorganic arsenic is methylated in the body by an alternating reduction of pentavalent arsenic to trivalent and addition of a methyl group. The major end metabolites are dimethylarsinic acid (DMA), monomethylarsonic acid (MMA) and inorganic arsenic [As(III) and arsenate (As(V))]. The biomethylation of arsenic in humans seems to be dependent on genetic polymorphisms, but average proportions in urine are 10-30\% inorganic arsenic, 10-20\% MMA and 60-70\% DMA (Vahter 2000).

The toxicity of arsenic in humans depends on its chemical forms: both inorganic and organic trivalent arsenicals are more potent toxicants than are the pentavalent forms (Hughes 2002). The 
arsenic methylation capacities are affected by gender, age, and ethnicity (Lindberg et al., 2008, Sun et al., 2007, Brima et al., 2006, Agusa et al., 2009b, 2010a, 2012). The increased primary methylation capacity, based on the ratio between MMA and inorganic arsenic [(As(III) and As(V)], suggests an association with an increased risk of arsenic-related skin lesions (McCarty et al., 2007, Tseng, 2007). Speciation of urinary arsenic into inorganic and organic forms and even the arsenic oxidation states gives a more definitive indication of the degree of exposure to inorganic arsenic (Hughes, 2006).

Vietnam, located in Southeast Asia, is an agricultural country with a population of 88 million. The residents are concentrated mainly in the Red River Delta in the North and in the Mekong River Delta in the South. For example, 18 million inhabitants presently live in the Red River Delta, with a density of about 1200 inhabitants $/ \mathrm{km}^{2}$, making this one of the most populous areas of the world. In the Red River Delta, groundwater pumped from the Holocene aquifer by household tube wells is commonly used as drinking water and for bathing and washing. Arsenic is released from Holocene sediments in the delta to groundwater due to reduction of Fe-oxide or organic matter (Postma et al., 2007). Recent study revealed that Pleistocene aquifer, which has low concentration of arsenic, is contaminated by arsenic through variations in groundwater flow conditions and redox state of sediments induced by pumping of groundwater (van Green et al., 2013). Arsenic contamination of groundwater in Vietnam was first discovered in the Hanoi region in 1998, with at an average concentration of $159 \mu \mathrm{g} / \mathrm{L}$ (Berg et al., 2001). This is fifteen times higher than the drinking water standard for arsenic in Vietnam $(10 \mu \mathrm{g} / \mathrm{L})($ Ministry of Health of Vietnam, 2002) and the WHO guideline for arsenic in drinking water (10 $\mu \mathrm{g} / \mathrm{L})(\mathrm{WHO}, 2004)$. The magnitude of groundwater arsenic contamination is therefore comparable to the situation in Bangladesh and West Bengal, India (Chowdhury et al., 2000).

The study by Berg et al. (2001) was followed by several publications that reported high arsenic contamination in groundwater of the Red River and the Mekong River Deltas (Agusa et al., 2006, 2009a, 2009b, 2009c, 2010b, 2012; Berg et al., 2006; Buschmann et al., 2008; Larsen et al., 
2008; Nguyen et al., 2009; Postma et al., 2010; Trang et al, 2005; Winkel et al., 2011). In many places in the Red River Delta, levels as high as a few tens of $\mathrm{mg} / \mathrm{L}$ of dissolved iron are present in groundwater. This water is not used directly, but is often treated by simple household sand filters in order to remove the iron. The additional effect of using the sand filters is a reduction in the arsenic level in the groundwater due to co-precipitation of arsenic onto the iron hydroxide in the sand bed (Tobias et al., 2011). The general sand filter arsenic removal efficiency is about $80 \%$ and is influenced by the abundance of dissolved iron, and to some degree by phosphate (Berg et al., 2006). However, although the filtration system can remove a certain level of arsenic, the sand filtered drinking water still occasionally exceeds the WHO guideline value of $10 \mu \mathrm{g} / \mathrm{L}$ (Agusa et al., 2009b, 2009c, 2010b, 2012; Berg et al., 2006; Nguyen et al., 2009).

Recently, monitoring data have been published for the arsenic burden in the human body and significant arsenic exposure was detected in local Vietnamese people (Agusa et al., 2006, 2009a, 2009b, 2012; Berg et al., 2007; Nguyen et al., 2009). However, these studies focused mainly on the larger Hanoi region and were undertaken with a limited sample number. Compared to the abundant data available for Bangladesh and India, the picture for arsenic exposure in humans in Vietnam, especially in the Red River Delta, seems rather meagre. In this article, we present a baseline study on arsenic exposure in humans from arsenic contaminated groundwater in the Red River Delta, Vietnam. Four villages were selected, including one reference village and three contaminated villages with different levels of arsenic in the groundwater. A total of 68 families were included in this study, providing 213 samples of hair and urine. Raw groundwater and sand-filtered water was also collected from the family-owned wells. Total arsenic was quantified in hair and the speciation of inorganic and organic arsenic was thoroughly assessed in urine, including arsenobetaine (AB), dimethylarsinic acid (DMA), monomethylarsonic acid (MMA) and inorganic arsenic (IA; As(III) and $\mathrm{As}(\mathrm{V}))($ Fig. S1). 


\section{Materials and methods}

\subsection{Sample collection}

The sampling campaigns were conducted in four villages, Tu Liem (R1- reference site), Dan Phuong (R2), Hoai Duc (R3), and Ly Nhan (R4) in the Red River Delta, Vietnam during 20042005 in cooperation with the local health station staff. Tu Liem, Dan Phuong, and Hoai Duc and Ly Nhan are located in the Northern part, the West side and the Middle of the Delta, respectively (Fig. 1). The investigated area is approximately $2-4 \mathrm{~km}^{2}$ for each site, which is the size of a typical village in the Red River Delta. All four villages are located in the rural area of the Red River Delta, most of the residents are farmers. Filter groundwater has been used as the main source for drinking water, especially in dry season. In rainy season, some families having big water storage tanks can collect rainy water for drinking and cooking.

Raw groundwater from the family wells and water used for drinking (i.e. sand sand-filtered or untreated water) was collected for each of the studied households. Tube well water was pumped for about 5-10 minutes to remove water at the tip of the tap and then samples were collected. In Dan Phuong (R2), Hoai Duc (R3) and Ly Nhan (R4), sand filters for iron and arsenic removal are very common. Filtered water samples were taken from the tank after tube well water had percolated through the sand bed. All water samples were filtered through $0.45 \mu \mathrm{m}$ membranes, stored in $200 \mathrm{~mL}$ PET bottles and then acidified to $\mathrm{pH}<2$ with $\mathrm{HNO}_{3}$ (APHA).

Both hair and urine samples were collected from members of the households where the water samples were taken. Mean age of total 68 families was 35.6 years. Mean percentages of female and male in each family were $41 \%$ and $59 \%$, respectively. Beforehand, the residents were informed about the purpose of the study by the local government health stations, where volunteers registered their consent to participate. Hair samples of about $3 \mathrm{~g}$ were cut at the terminal end near the scalp and at the scruff. The hair was stored in tightly closed clean polyethylene bags. All the hair and water samples were transferred to the laboratory of CETASD, Hanoi University of Science for total arsenic analysis. Spot $30 \mathrm{~mL}$ urine samples were collected in PET bottles and kept at -20 
${ }^{\circ} \mathrm{C}$. Urine samples were shipped frozen to the laboratory at CMES, Ehime University, Japan, for arsenic speciation. PET bottles were previously washed with dilute acid and rinsed with deionised Milli-Q water. The numbers of collected samples are summarized in Table 1. More detail information on age and sex disaggregated data are shown in supplemental Table S1.

\subsection{Chemical analysis}

The quantification of total inorganic arsenic in water samples was initiated by first reducing any $\mathrm{As}(\mathrm{V})$ present in the water to As(III) with NaI and ascorbic acid. The As (III) was then hydrided with $\mathrm{NaBH}_{4}$ in an acidic environment. The volatile $\mathrm{AsH}_{3}$ was determined by hydride generation-atomic absorption spectroscopy (AA6800-Shimadzu). A calibration curve was established with the concentration range of $1-10 \mu \mathrm{g} / \mathrm{L}, R^{2}>0.995$, using an AAS arsenic standard solution $(1000 \mu \mathrm{g} / \mathrm{L}$, Fluka).

The treatment procedure of hair samples for total arsenic analysis was conducted according to previously published references (De Moraes Flores et al., 2001; Rahman et al., 2000) with some modifications. Briefly, the hair samples were soaked and washed with neutral shampoo, rigorously cleaned, rinsed with deionised Milli-Q water (Millipore) and then dried at $60{ }^{\circ} \mathrm{C}$. A $0.3 \mathrm{~g}$ portion of cleaned hair sample was soaked in $3 \mathrm{~mL} 65 \% \mathrm{HNO}_{3}$ and $1 \mathrm{~mL} 30 \% \mathrm{H}_{2} \mathrm{O}_{2}$ in a Teflon thimble and then heated in a microwave oven at $300-600 \mathrm{~W}$ power for 38 minutes. $\mathrm{A} \mathrm{HSO}_{3} \mathrm{NH}_{2}$ solution was then added to the digest to a concentration of $30 \mathrm{mM} / \mathrm{L}$ in order to eliminate nitro-oxides (De Moraes Flores et al., 2001). The subsequent steps were as described for the water samples.

Quality assurance was ensured and the analytical methods were controlled using certified reference solutions such as the ICP Multi-element standard IX (Merck) and SPD-SW2 (Spectra Pure Standards). The certified reference hair material (NCSZC81002-Promochem, GBW09101) was also used to check the recovery of the hair treatment procedure. The average result from 9 tests $(0.58 \pm 0.03 \mathrm{mg} / \mathrm{kg})$ was in excellent agreement with the certified value $(0.59 \pm 0.07 \mathrm{mg} / \mathrm{kg})$. All acids and chemicals used in the study were PA grade from Merck. 
The urine samples kept at $-20{ }^{\circ} \mathrm{C}$ were thawed at room temperature and a $2 \mathrm{~mL}$ portion was filtered through a $0.25 \mu \mathrm{m}$ membrane. The samples were diluted five times by weighing, using deionised water (Milli-Q). The following compounds in urine samples were determined with a high performance liquid chromatograph (HPLC; LC10A Series, Shimadzu) coupled with an inductively coupled plasma mass spectrometer (ICP-MS; HP-4500, Hewlett-Packard); AB, DMA, MMA and inorganic arsenic (IA; As (III) and As (V)) (Agusa et al., 2009a). The HPLC column, mobile phase, flow rate and injection volume for analysis of arsenic species were Shodex Asahipak ES 502N7C (10 cm X $7.6 \mathrm{~mm} \mathrm{id),} 15 \mathrm{mM}$ citric acid monohydrate $(\mathrm{pH} 2.0), 1.0 \mathrm{~mL} / \mathrm{min}$, and $20 \mu \mathrm{L}$, respectively. The standard solutions were prepared with the range of concentrations of $1,5,25,50$, and $100 \mu \mathrm{g} / \mathrm{L}$ for each compound and $\mathrm{R}^{2}$ values were higher than 0.995 (Mandal et al., 2001). The certified reference sample NIES No. 18 Human Urine was used in the analytical procedures and good recoveries (90-106\%) were obtained for AB and DMA.

Analysis of creatinine in urine samples was commissioned to SRL Inc. (Tokyo, Japan). Concentrations of arsenic compounds in urine are expressed on a creatinine basis ( $\mu \mathrm{g} / \mathrm{g}$ creatinine).

\subsection{Statistical analysis}

All statistical analyses were performed with Stat View (version 5.0, SAS Institute) and SPSS (version 18.0, SPSS Inc.). Before statistical analysis, one-half of concentration of the respective limit of detection was substituted for those values below the limit of detection. All data were tested for goodness of fit to a normal distribution with a Kolmogorov-Smirnov's one sample test. Concentrations of water arsenic and urinary arsenic compounds were log-transformed because these data did not show normal distributions. Regional differences in arsenic concentrations in water and urine samples were assessed by analysis of variance (ANOVA), followed by Tukey-Kramer post hoc tests. Effects of sex, age and arsenic exposure level (based on concentrations of arsenic in filtered groundwater: all subjects were divided into two groups, $<50 \mu \mathrm{g} / \mathrm{L}$ and $\geq 50 \mu \mathrm{g} / \mathrm{L}$ ) on arsenic concentration in urine and on methylation capacities (MMA/IA and DMA/MMA) were examined 
by multi-way ANOVA. A linear regression analysis was used to measure the strength of the association between variables. In this study, a p value of less than 0.05 was considered to indicate statistical significance.

\section{Results and Discussion}

\subsection{Arsenic polluted groundwater and the decrease of arsenic in sand filtered water}

The arsenic concentrations in groundwater of the studied sites are presented in Table 1. Concentrations of arsenic in groundwater were highest in Ly Nhan (geometric mean (GM), 420 $\mu \mathrm{g} / \mathrm{L}$ ), followed by Hoai Duc (GM, $133 \mu \mathrm{g} / \mathrm{L})$, Dan Phuong (GM, $43 \mu \mathrm{g} / \mathrm{L}$ ), and Tu Liem (where all water samples had $<1 \mu \mathrm{g} / \mathrm{L})(p<0.001)$.

The distribution of arsenic concentrations in the individual groundwater samples is plotted in Figure 2. The arsenic criteria for drinking water according to the Vietnamese standard and the WHO guideline are $10 \mu \mathrm{g} / \mathrm{L}$ (Ministry of Health of Vietnam, 2002; WHO, 2004). Chakraborti et al. (2003) reported that the concentration of drinking water predicting arsenic skin lesions is $300 \mu \mathrm{g} / \mathrm{L}$. In Ly Nhan, arsenic concentrations in any of the groundwater samples $(311-598 \mu \mathrm{g} / \mathrm{L})$ exceeded this threshold value; $86 \%$ of the wells at Hoai Duc did not meet the criteria for drinking established by Vietnam (Ministry of Health of Vietnam, 2002) and WHO (WHO, 2004) and 51\% of the wells contained arsenic at levels higher than $300 \mu \mathrm{g} / \mathrm{L}$ (Chakraborti et al., 2003). At Dan Phuong, 69\% and $38 \%$ of groundwater samples had higher arsenic concentrations than the criteria of the WHO and Vietnam, and skin lesions, respectively. These results suggest that arsenic contamination in groundwater is widely distributed in the Red River Delta and the high risk of arsenic toxicity is of great concern for residents in these regions.

Figure 2 also shows that the distributions of arsenic concentrations were homogenous in Ly Nhan and Hoai Duc, and heterogeneous in Dan Phuong. The phenomena were observed in other 
studies in the Red River Delta, but the causes of this variation still need further studies (Berg et al., 2001, 2007).

The people in Dan Phuong, Ly Nhan and Hoai Duc use sand filter systems, whose purpose is to reduce iron compounds originally present in groundwater in the Red River Delta (Tobias et al., 2011. The side benefit of this is the marked amount of arsenic also removed by absorption onto the iron hydroxide formed in the sand bed (Berg 2006). Geometric mean concentrations of arsenic in the sand filtered water samples collected from Dan Phuong, Ly Nhan, and Hoai Duc were 10, 23, and $74 \mu \mathrm{g} / \mathrm{L}$, respectively (Table 1$)(p<0.001)$. This was a decrease compared to the original levels of arsenic in groundwater, especially in the samples from Dan Phuong and Ly Nhan, where the average arsenic removal efficiencies of the sand filters were 85 and $91 \%$, respectively. These removals were comparable with previously reported results, as more than $80 \%$ of arsenic in water could be removed by the household sand filters on an arithmetic mean base (Agusa et al., 2009b, 2012; Berg et al., 2006). However, the sand filters in Hoai Duc trapped only $43 \%$ of arsenic present in raw groundwater. Arsenic removal efficiencies of the sand filters are known to increase with iron concentrations in the water (Berg et al., 2006; Meng et al., 2001). Indeed, the arithmetic mean concentrations of iron were higher in the groundwater from Dan Phuong $(12.1 \mathrm{mg} / \mathrm{L})$ and Ly Nhan $(15 \mathrm{mg} / \mathrm{L})$ than from Hoai Duc $(6.3 \mathrm{mg} / \mathrm{L})($ Unpublished results). Hence, the low removal efficiency of arsenic by the sand filter in Hoai Duc may be partly explained by the low content of iron in the groundwater in that area.

Assuming that the people always used the water treated by sand filters and their arsenic filter yields are stable all the times, the actual arsenic exposures of the people in the studied villages are reduced significantly. However, even though sand filtration is useful for removal of arsenic from groundwater, several water samples still had arsenic concentrations higher than the WHO (WHO, 2004) and Vietnam (Ministry of Health of Vietnam, 2002) guideline values; for example, the sample ratios were 54\% in Dan Phuong, $80 \%$ in Ly Nhan, and 86\% in Hoai Duc (Fig. 2), indicating these contaminated water are not suitable for drinking. Since 18 million people live in the Red 
River Delta, the potential for serious health effects in the mass community should be a major concern.

\subsection{Arsenic levels in human hair}

We analysed total arsenic in 213 hair samples from the residents living in the four villages along the Red River Delta; the concentration was in the range of 0.07-7.51 $\mu \mathrm{g} / \mathrm{g}$ (Table 1). At Tu Liem, where arsenic levels in water were $<1 \mu \mathrm{g} / \mathrm{L}$, the GM for the arsenic concentration in hair was $0.29 \mu \mathrm{g} / \mathrm{g}$, a value that was comparable to those from nonexposed populations in the West Bengal $(0.3 \mu \mathrm{g} / \mathrm{g})$ and Egypt $(0.04-1.04 \mu \mathrm{g} / \mathrm{g})$ (Mahata et al., 2003; Saad and Hassanien, 2001). On the other hand, arsenic concentrations were significantly higher in hair of residents from Dan Phuong (GM, $0.45 \mu \mathrm{g} / \mathrm{g})$, Ly Nhan (GM, $0.62 \mu \mathrm{g} / \mathrm{g})$ and Hoai Duc (GM, $1.15 \mu \mathrm{g} / \mathrm{g})$ than from Tu Liem $(p<$ 0.001 ). About $34 \%$ of local residents showed hair arsenic concentrations over $1 \mu \mathrm{g} / \mathrm{g}$, which might be related to skin pathology (Chakraborty et al., 2003). The results reveal that the potential for arsenicosis patients should be carefully examined in order to provide appropriate mitigation measures.

The plots of the arsenic levels in the hair against those in the groundwater and sand filtered water samples showed significant positive correlations, but the $R^{2}$ values of the regression equation were higher for filtered water (0.394) (Fig. 3a) than for groundwater (0.305). This could be explained, as already mentioned, by the fact that the filtered groundwater from the sand filter tanks is used for drinking in many parts of the Red River Delta instead of raw groundwater. The concentration of arsenic in the sand filtered water, which results in hair arsenic concentrations that reach the threshold level $(1 \mu \mathrm{g} / \mathrm{g})$ (Chakraborty et al., 2003), was estimated to be $96 \mu \mathrm{g} / \mathrm{L}$ (95\% confidence interval (IC), $68-144 \mu \mathrm{g} / \mathrm{L}$ ) by the regression analysis. Furthermore, when all the hair data from all four villages were combined and evaluated by the cut off value of $50 \mu \mathrm{g}$ arsenic per litre in the sand filtered water (high exposure group, $\geq 50 \mu \mathrm{g} / \mathrm{L}$ and low exposure group, $<50 \mu \mathrm{g} / \mathrm{L}$ ), the hair arsenic concentration was significantly higher in the high exposure group than in the low 
exposure group. In addition, the ratio of subjects who showed hair arsenic concentrations $\geq 1 \mu \mathrm{g} / \mathrm{g}$ was $64 \%$ in the high exposure group, while it was only $8 \%$ in the low exposure group $(p<0.001)$. These results indicate that local people are exposed to arsenic from intake of sand filtered groundwater and that the populations with high arsenic exposure are at risk for arsenic intoxication.

Interestingly, we found that some subjects ingesting filtered water with less than $10 \mu \mathrm{g} / \mathrm{L}$ of arsenic had concentrations of arsenic in hair higher than $1 \mu \mathrm{g} / \mathrm{g}$ (Fig. 3a). This might be explained by the finding that, in countries where arsenic contamination in groundwater is prominent, as in Vietnam, groundwater is not only used for drinking but also for irrigation. The arsenic uptake sources in to the human body could be food in addition to water. The people who drink arsenic-free water may still take in arsenic from rice or vegetables cultured with arsenic contaminated groundwater (Uchino et al., 2006).

\subsection{Arsenic species in urine samples}

Concentrations of total arsenic and individual arsenic species AB, DMA, MMA and IA in human urine are presented in Table 1. Urinary arsenic concentrations were significantly higher in residents from Hoai Duc (GM, $98 \mu \mathrm{g} / \mathrm{g}$ creatinine) and Dan Phuong (GM, $88 \mu \mathrm{g} / \mathrm{g}$ creatinine) than in residents from Ly Nhan (GM, $60 \mu \mathrm{g} / \mathrm{g}$ creatinine) and Tu Liem (GM, $51 \mu \mathrm{g} / \mathrm{g}$ creatinine) $(p<$ 0.001). In general, DMA was the predominant arsenic species in human urine, followed by AB, IA and MMA. Arsenobetaine (AB) is mainly found in seafood and thus the source seemed to be seafood consumption. On the other hand, IA accumulation is related to uptake of drinking water and ingested IA is metabolized to MMA and then DMA in the human body. Thus, for understanding IA exposure using urine, IA and its metabolites (MMA and DMA) can be more useful indicators than total arsenic. For IMD (IA + MMA + DMA), the concentration in urine of residents from each location, in decreasing order, was: Hoai Duc (GM, $85 \mu \mathrm{g} / \mathrm{g}$ creatinine) $\approx$ Dan Phuong (GM, $77 \mu \mathrm{g} / \mathrm{g}$ creatinine) $>$ Ly Nhan $(\mathrm{GM}, 53 \mu \mathrm{g} / \mathrm{g}$ creatinine $)>\mathrm{Tu}$ Liem $(\mathrm{GM}, 29 \mu \mathrm{g} / \mathrm{g}$ creatinine $)(p<0.001)$. Together with the hair data, the data from urine also confirmed that 
residents living in Hoai Duc are suffering from a more severe arsenic contamination from groundwater compared to the residents in the other villages.

The relationship between IMD in urine samples and arsenic in the sand filtered water samples showed a significant positive correlation (Fig. 3b) $(p=0.002)$. Furthermore, the GMs of urinary IMD, MMA and DMA concentrations were significantly higher in the high exposure group than in the low exposure group $(p<0.01)$. Similar to the results of human hair, these findings indicate that the water is a significant source of arsenic for these residents. A significant positive relationship between concentrations of IMD in urine and arsenic in hair was also detected (Fig. 3c). Hair is known to be a good indicator of past arsenic exposure, while arsenic concentration in urine represents recent exposure to arsenic (Mandal and Suzuki, 2002). Therefore, our results indicate that the residents may have been chronically exposed to arsenic derived from groundwater.

On the contrary, no significant correlation was found for urinary AB concentration with filtered water arsenic level $(p>0.05)$ and no significant difference was noted in AB concentrations in urine between the high and low exposure groups $(p>0.05)$. In urine samples from an unexposed population or from recent seafood consumers, $\mathrm{AB}$ was often observed in urine in proportions as high as 50-80\% (Brima et al., 2006; Lai et al., 2004).

No significant differences were found for the percentages of arsenic species between the high and low exposure groups except for MMA (AM, 9.9\% in high exposure group and 7.7\% in low exposure group, $p=0.006$ ). Several studies have reported that the MMA percentage increased in groups exposed to high arsenic levels (Sun et al., 2007). A review article by Tseng (2007) revealed that the increased MMA percentage, decreased DMA or decreased DMA/MMA ratio in human urine was associated with skin lesions, cancer and noncancer bone diseases due to arsenic intoxication. In our study case, the increase in the MMA percentage was small (from 7.7 to $9.9 \%$ ) and the absolute values were lower than those reported in other countries where the arsenicosis patients were observed; for example, the MMA percentage values observed in China were as high as $13-17 \%$ (Sun et al., 2007), 13-15\% in Taiwan (Hsueh et al., 2003; Tseng, 2007) and 14\% in 
Bangladesh (Chung et al., 2002; McCarty et al., 2007). No significant differences were seen in urinary DMA/MMA and MMA/IA rations between the high and low exposure groups in the present study $(p>0.05)$.

\subsection{Effects of sex, age and exposure status on arsenic accumulation and metabolism}

Multivariate analysis was used to establish the associations of sex, age and arsenic exposure status based on arsenic concentration in ingested water, their interactions with arsenic concentrations in hair and urine, and the metabolic capacity of arsenic (Table 2). Concentrations of hair arsenic and urinary arsenic and IMD, and compositions of $\mathrm{AB}$ and MMA in urine, were significantly associated only with arsenic exposure status. As we explained earlier, these values, except for $\mathrm{AB} \%$, were significantly higher in the high exposure group than in the low exposure group. For $\mathrm{AB} \%$, a higher value was found for the low exposure group than for the high exposure group, although the difference was not statistically significant according to the t-test $(p>0.05)$. Because IMD \% showed the opposite trend (but again not statistically significant), significant negative correlations between $\mathrm{AB} \%$ and $\mathrm{DMA} \%$, MMA $\%$ and IA $\%$ were detected $(\mathrm{p}<0.001)$. The urinary $A B$ level itself was not significantly correlated with arsenic exposure status, but this result was observed by multi-way ANOVA.

Age and sex were significantly associated with urinary IA\% and MMA/IA, and urinary MMA\% and DMA/MMA, respectively (Table 2). Simple linear regression analyses revealed that the value of IA $\%$ decreased with age $(p=0.042)$, while MMA/IA increased with age $(p<0.001)$. Our previous multiple regression analysis studies also showed a positive correlation between MMA/IA and age in Vietnamese people (Agusa et al., 2009b. 2010a). Interestingly, significant cointeraction with age and arsenic exposure was detected for hair arsenic and urinary IMD concentrations, and MMA\% in urine (Fig. 4). In the case of arsenic in the hair, the concentration decreased with age but only in the high arsenic exposure group $(p<0.001)$ (Fig. 4a). This suggests that decreased water consumption by the elderly might result in a reduction in arsenic exposure. 
Positive correlations of age with concentration of IMD and MMA\% in human urine were found in the low arsenic exposure group $(p<0.05)$ (Figs. $4 \mathrm{~b}$ and $4 \mathrm{c}$ ), indicating that arsenic exposure influences age-dependent urinary excretion of arsenic and methylation capacity, although the underlying mechanism is still unclear.

Gender differences indicated that MMA\% was significantly higher in the urine of males than of females $(p=0.010)$. On the other hand, elevated DMA/MMA was found in females $(p=0.019)$. In our previous study, urinary DMA/MMA was significantly higher in females than males from the Red River Delta, while the opposite result was observed for MMA\% (Agusa et al., 2010b). Similar results have been reported for other populations from arsenic-contaminated areas (Tseng et al., 2005). These results suggest that, in general, females have a higher metabolic capacity to produce DMA from IA than do males.

\section{Conclusions}

In conclusion, the arsenic exposure in humans in the villages in the Red River Delta, Vietnam, studied here is predominantly expressed as elevated arsenic contents in the hair and urine samples. In the arsenic contaminated villages $(\geq 50 \mu \mathrm{g} / \mathrm{L}$ of arsenic concentration in water), about $64 \%$ hair samples contained arsenic at levels higher than $1 \mu \mathrm{g} / \mathrm{g}$, which is the level associated with arsenic intoxication diseases. Our results also revealed that the sum of arsenicals excreted in urine and the primary methylation, expressed as MMA percentage, are significantly higher in individuals exposed to high arsenic $(\geq 50 \mu \mathrm{g} / \mathrm{L})$ than to low arsenic $(<50 \mu \mathrm{g} / \mathrm{L})$ in drinking water. The present study revealed that age was important factor influencing urinary IA\% and MMA/IA. Furthermore, significant co-interaction of age and arsenic exposure stats was detected for hair arsenic and urinary IMD concentrations and MMA\% in urine in this study. In the previous epidemiological investigations in arsenic contaminated groundwater areas, significant high risks of black foot disease (Tseng et al., 1977), skin lesions (Cebrian et al., 1983) and diabetes (Tseng et al, 2000) were 
observed in older age people with high arsenic exposure. Further studies are required to understand the associations of age and exposure level and methylation capacity of arsenic with arsenic-related disease.

The health of residents living in the Red River Delta is likely to be harmed if this level of exposure continues without any mitigation measures. The use of sand filters clearly reduces arsenic exposure and accumulation in the human body. However, because even sand-filtered water often contains arsenic levels of chronic toxicity, the human health risk due to arsenic exposure and its mitigation must be seriously considered in Vietnam. Hence, it is not surprising that health problems related to arsenic ingestion through drinking water are increasingly reported in Vietnamese newspapers.

\section{Acknowledgements}

This study was substantially funded by 105.09.59.09 NAFOSTED support for CETASD, the Swiss Agency for Development and Cooperation (SDC) in the framework of the Swiss-Vietnamese cooperation project (ESTNV), Core University Program funded by the Japanese Government (JSPS) and 21st Century COE Program from the Ministry of Education, Culture, Sports, Science and Technology, Japan. We thank Nguyen Thi Minh Hue, Bui Hong Nhat, Pham Thi Dau, Tran Thi Hao and Dao Manh Phu for contributions in the field and laboratory work.

\section{References}

Agusa T, Kunito T, Fujihara J, Kubota R, Minh TB, Trang PTK, et al. Contamination by arsenic and other trace elements in tube-well water and its risk assessment to humans in Hanoi, Vietnam. Environ Pollut 2006; 139: 95-106.

Agusa T, Kunito T, Minh TB, Kim Trang PT, Iwata H, Viet PH, et al. Relationship of urinary arsenic metabolites to intake estimates in residents of the Red River Delta, Vietnam. Environ Pollut 2009a; 157: 396-403.

Agusa T, Iwata H, Fujihara J, Kunito T, Takeshita H, Minh TB, et al. Genetic polymorphisms in AS3MT and arsenic metabolism in residents of the Red River Delta, Vietnam. Toxicol Appl Pharmacol 2009b; 236: 131-141.

Agusa T, Inoue S, Kunito T, Minh TB, Ha NN, Tu NPC, et al. Human exposure to arsenic from 
groundwater in the Red River and Mekong River Deltas in Vietnam. Int J Environ Stud 2009c; 66: 49-57.

Agusa T, Iwata H, Fujihara J, Kunito T, Takeshita H, Tu BM, et al. Genetic polymorphisms in glutathione S-transferase (GST) superfamily and arsenic metabolism in residents of the Red River Delta, Vietnam. Toxicol Appl Pharmacol 2010a; 242: 352-362.

Agusa T, Kunito T, Kubota R, Inoue S, Fujihara J, Minh TB, et al. Exposure, metabolism, and health effects of arsenic in residents from arsenic-contaminated groundwater areas of Vietnam and Cambodia: A review. Rev Environ Health 2010b; 25: 193-220.

Agusa T, Fujihara J, Takeshita H, Iwata $\mathrm{H}$. Individual variations in inorganic arsenic metabolism associated with AS3MT genetic polymorphisms. International Journal of Molecular Sciences 2011; 12: 2351-2382.

Agusa T, Kunito T, Tue NM, Lan VTM, Fujihara J, Takeshita H, et al. Individual variations in arsenic metabolism in Vietnamese: The association with arsenic exposure and GSTP1 genetic polymorphism. Metallomics 2012; 4: 91-100.

Ahmad SA, Salim Ullah Sayed MH, Barua S, Haque Khan M, Faruquee MH, Jalil A, et al. Arsenic in drinking water and pregnancy outcomes. Environ Health Perspect 2001; 109: 629-631.

Berg M, Tran HC, Nguyen TC, Pham HV, Schertenleib R, Giger W. Arsenic contamination of groundwater and drinking water in Vietnam: A human health threat. Environ Sci Technol 2001; 35: 2621-2626.

Berg M, Luzi S, Trang PTK, Viet PH, Giger W, St广`年en D. Arsenic removal from groundwater by household sand filters: Comparative field study, model calculations, and health benefits. Environ Sci Technol 2006; 40: 5567-5573.

Berg M, Stengel C, Pham TK, Pham HV, Sampson ML, Leng M, et al. Magnitude of arsenic pollution in the Mekong and Red River Deltas - Cambodia and Vietnam. Sci Total Environ 2007; 372: 413-25.

Brima EI, Haris PI, Jenkins RO, Polya DA, Gault AG, Harrington CF. Understanding arsenic metabolism through a comparative study of arsenic levels in the urine, hair and fingernails of healthy volunteers from three unexposed ethnic groups in the United Kingdom. Toxicol Appl Pharmacol 2006; 216: 122-130.

Buschmann J, Berg M, Stengel C, Winkel L, Sampson ML, Trang PTK, et al. Contamination of drinking water resources in the Mekong delta floodplains: Arsenic and other trace metals pose serious health risks to population. Environ Int 2008; 34: 756-764.

Chakraborti D, Mukherjee SC, Pati S, Sengupta MK, Rahman MM, Chowdhury UK, et al. Arsenic groundwater contamination in Middle Ganga Plain, Bihar, India: a future danger? Environ Health Perspect 2003; 111: 1194-1201.

Chen CJ, Hsu LI, Wang CH, Shih WL, Hsu YH, Tseng MP, et al. Biomarkers of exposure, effect, and susceptibility of arsenic-induced health hazards in Taiwan. Toxicol Appl Pharmacol 2005; 206: 198-206.

Chowdhury UK, Biswas BK, Chowdhury TR, Samanta G, Mandal BK, Basu GC, et al. Groundwater arsenic contamination in Bangladesh and West Bengal, India. Environ Health Perspect 2000; 108: 393-397. 
Chung JS, Kalman DA, Moore LE, Kosnett MJ, Arroyo AP, Beeris M, et al. Family correlations of arsenic methylation patterns in children and parents exposed to high concentrations of arsenic in drinking water. Environ Health Perspect 2002; 110: 729-733.

De Moraes Flores EM, Da Silva LLC, Barin JS, Saidelles APF, Zanella R, Dressler VL, et al. Minimization of volatile nitrogen oxides interference in the determination of arsenic by hydride generation atomic absorption spectrometry. Spectrochimica Acta - Part B Atomic Spectroscopy 2001; 56: 1883-1891.

Hsueh Y-M, Ko Y-F, Huang Y-K, Chen H-W, Chiou H-Y, Huang Y-L, et al. Determinants of inorganic arsenic methylation capability among residents of the Lanyang Basin, Taiwan: arsenic and selenium exposure and alcohol consumption. Toxicol Lett 2003; 137: 49-63.

Hughes MF. Arsenic toxicity and potential mechanisms of action. Toxicol Lett 2002; 133: 1-16.

Hughes MF. Biomarkers of exposure: A case study with inorganic arsenic. Environ Health Perspect 2006; 114: 1790-1796.

Lai VWM, Sun Y, Ting E, Cullen WR, Reimer KJ. Arsenic speciation in human urine: Are we all the same? Toxicol Appl Pharmacol 2004; 198: 297-306.

Larsen F, Pham NQ, Dang ND, Postma D, Jessen S, Pham VH, et al. Controlling geological and hydrogeological processes in an arsenic contaminated aquifer on the Red River flood plain, Vietnam. Appl Geochem 2008; 23: 3099-3115.

Lindberg AL, Ekström EC, Nermell B, Rahman M, Lönnerdal B, Persson LA, et al. Gender and age differences in the metabolism of inorganic arsenic in a highly exposed population in Bangladesh. Environ Res 2008; 106: 110-120.

Mahata J, Basu A, Ghoshal S, Sarkar JN, Roy AK, Poddar G, et al. Chromosomal aberrations and sister chromatid exchanges in individuals exposed to arsenic through drinking water in West Bengal, India. Mutation Research - Genetic Toxicology and Environmental Mutagenesis 2003; 534: 133-143.

Mandal BK, Ogra Y, Suzuki KT. Identification of dimethylarsinous and monomethylarsonous acids in human urine of the arsenic-affected areas in West Bengal, India. Chem Res Toxicol 2001; 14: $371-378$.

Mandal BK, Suzuki KT. Arsenic round the world: a review. Talanta 2002; 58: 201-235.

McCarty KM, Chen YC, Quamruzzaman Q, Rahman M, Mahiuddin G, Hsueh YM, et al. Arsenic methylation, GSTT1, GSTM1, GSTP1 polymorphisms, and skin lesions. Environ Health Perspect 2007; 115: 341-345.

Meng X, Korfiatis GP, Christodoulatos C, Bang S. Treatment of arsenic in Bangladesh well water using a household co-precipitation and filtration system. Water Res. 35, 2001, pp. 2805-10.

Milton AH, Smith W, Rahman B, Hasan Z, Kulsum U, Dear K, et al. Chronic arsenic exposure and adverse pregnancy outcomes in Bangladesh. Epidemiology 2005; 16: 82-86.

Ministry of Health of Vietnam. Drinking water hygienic standards. Hanoi. 2002

Nguyen VA, Bang S, Viet PH, Kim KW. Contamination of groundwater and risk assessment for arsenic exposure in Ha Nam province, Vietnam. Environ Int 2009; 35: 466-472. 
Postma D, Larsen F, Minh Hue NT, Duc MT, Viet PH, Nhan PQ, et al. Arsenic in groundwater of the Red River floodplain, Vietnam: Controlling geochemical processes and reactive transport modeling. Geochim Cosmochim Acta 2007; 71: 5054-5071.

Postma D, Jessen S, Hue NTM, Duc MT, Koch CB, Viet PH, et al. Mobilization of arsenic and iron from Red River floodplain sediments, Vietnam. Geochim Cosmochim Acta 2010; 74: 33673381 .

Rahman L, Corns WT, Bryce DW, Stockwell PB. Determination of mercury, selenium, bismuth, arsenic and antimony in human hair by microwave digestion atomic fluorescence spectrometry. Talanta 2000; 52: 833-843.

Rahman MM, Chowdhury UK, Mukherjee SC, Mondal BK, Paul K, Lodh D, et al. Chronic arsenic toxicity in Bangladesh and West Bengal, India - A review and commentary. J Toxicol, Clin Toxicol 2001; 39: 683-700.

Saad A, Hassanien MA. Assessment of arsenic level in the hair of the nonoccupational Egyptian population: Pilot study. Environ Int 2001; 27: 471-478.

Sun G, Xu Y, Li X, Jin Y, Li B, Sun X. Urinary arsenic metabolites in children and adults exposed to arsenic in drinking water in Inner Mongolia, China. Environ Health Perspect 2007; 115: 648-652.

Tobias R, Berg M. Sustainable Use of Arsenic-Removing Sand Filters in Vietnam: Psychological and Social Factors. Environ Sci Technol 2011; 45: 3260-3267.

Trang PTK, Berg M, Viet PH, Van Mui N, Van Der Meer JR. Bacterial bioassay for rapid and accurate analysis of arsenic in highly variable groundwater samples. Environ Sci Technol 2005; 39: 7625-7630.

Tseng C-H, Huang Y-K, Huang Y-L, Chung C-J, Yang M-H, Chen C-J, et al. Arsenic exposure, urinary arsenic speciation, and peripheral vascular disease in blackfoot diseasehyperendemic villages in Taiwan. Toxicol Appl Pharmacol 2005; 206: 299-308.

Tseng $\mathrm{CH}$. Arsenic methylation, urinary arsenic metabolites and human diseases: Current perspective. J Environ Sci Health C Environ Carcinog Ecotoxicol Rev 2007; 25: 1-22.

Uchino T, Roychowdhury T, Ando M, Tokunaga H. Intake of arsenic from water, food composites and excretion through urine, hair from a studied population in West Bengal, India. Food Chem Toxicol 2006; 44: 455-461.

Vahter M. Genetic polymorphism in the biotransformation of inorganic arsenic and its role in toxicity. Toxicol Lett 2000; 112: 209-217.

Van Geen A, Bostick BC, Thi Kim Trang P, Lan VM, Mai NN, Manh PD, et al. Retardation of arsenic transport through a Pleistocene aquifer. Nature 2013; 501: 204-207.

WHO, 2004. Guidelines for Drinking Water Quality, $3^{\text {rd }}$ edition. World Health Organization, Geneva, Switzerland.

Winkel LHE, Trang PTK, Lan VM, Stengel C, Amini M, Ha NT, et al. Arsenic pollution of groundwater in Vietnam exacerbated by deep aquifer exploitation for more than a century. Proc Natl Acad Sci U S A 2011; 108: 1246-1251. 


\section{Figures}

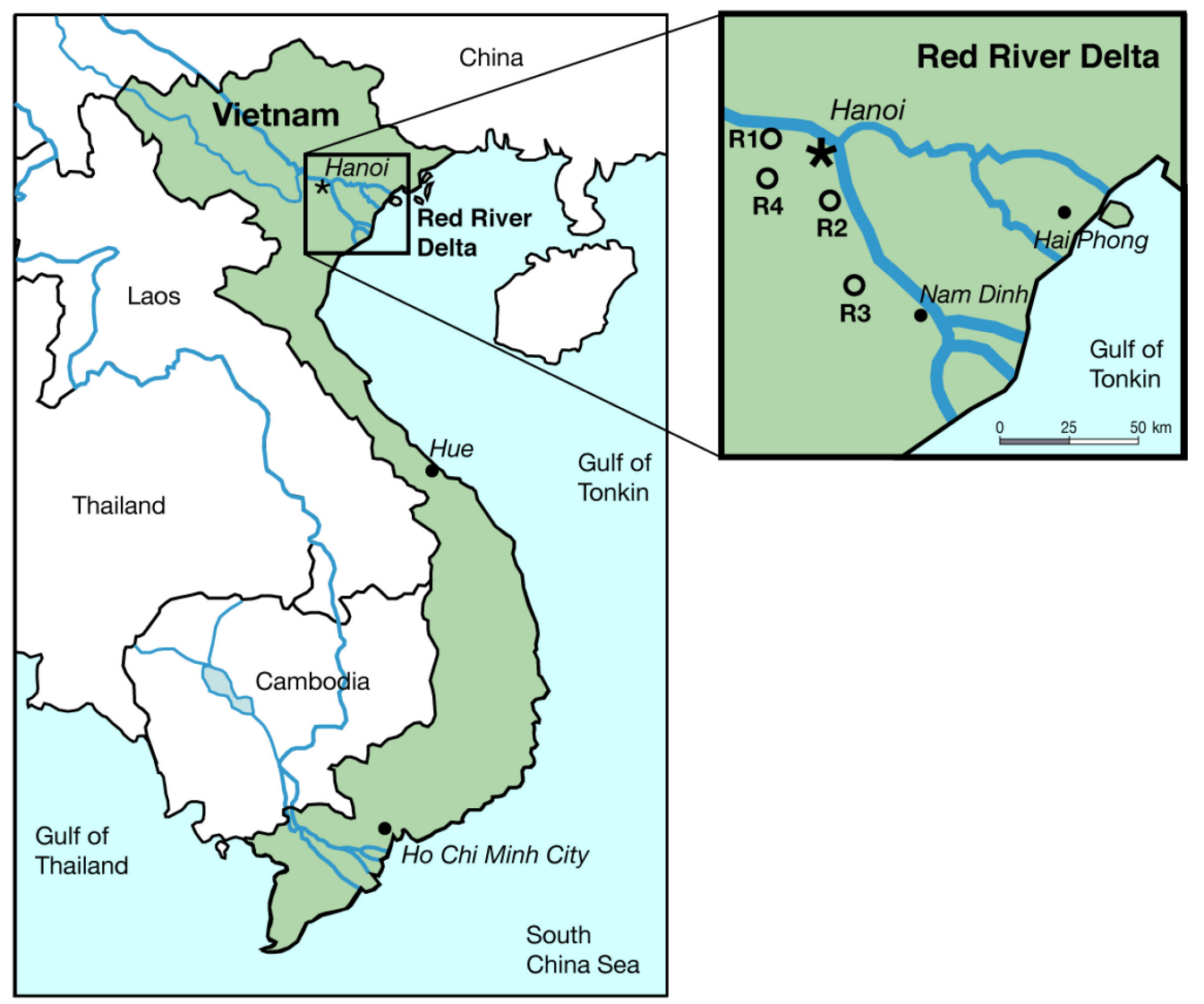

Fig. 1. Map of Vietnam indicating the sampled villages in the Red River Delta (R1; Tu Liem, R2;

Dan Phuong, R3; Hoai Duc, R4; Ly Nhan). 


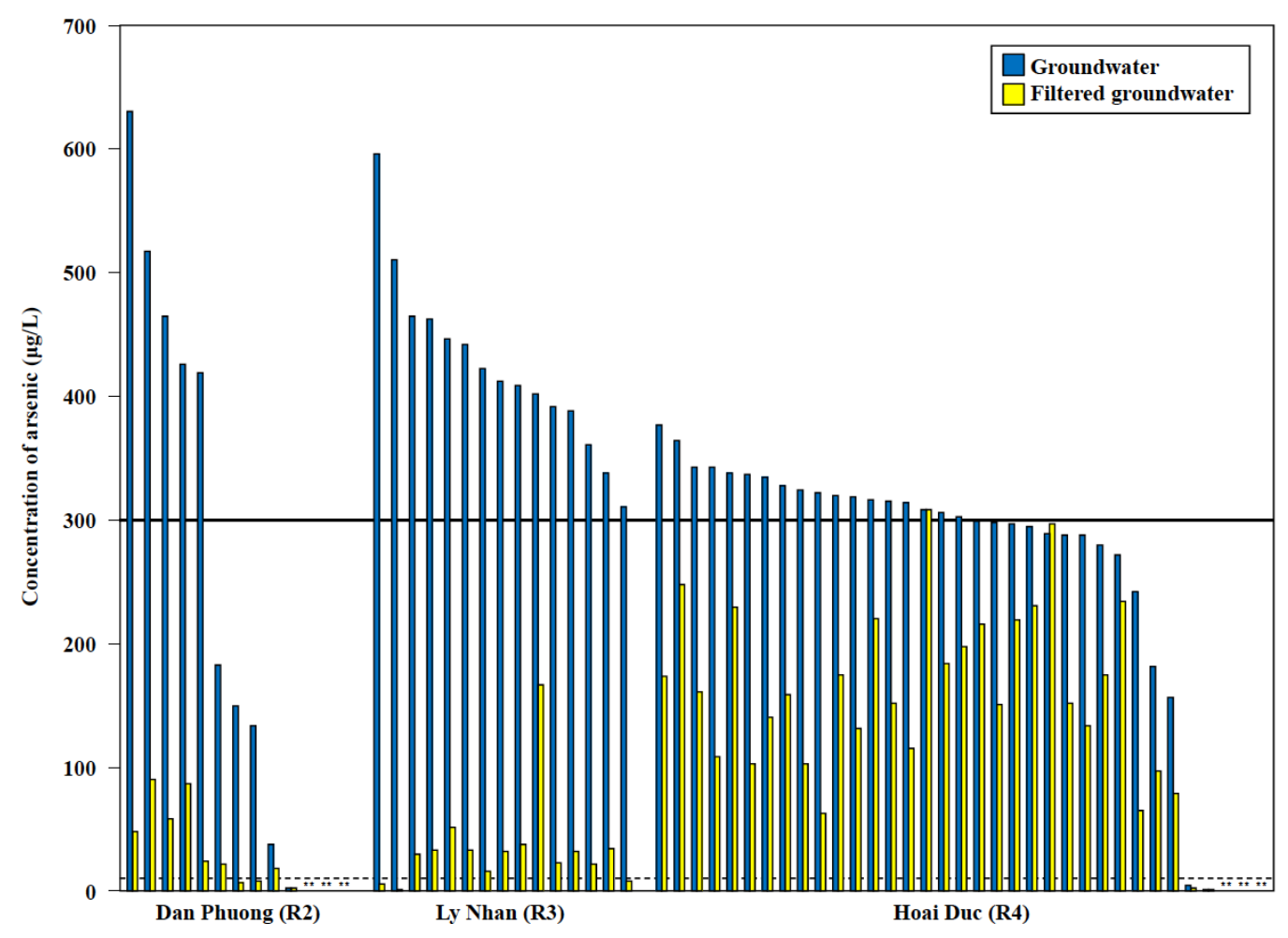

Fig. 2. Arsenic concentrations in raw groundwater and sand-filtered water that is used as drinking water in the studied villages of Dan Phuong (R2), Ly Nhan (R3), and Hoai Duc (R4). * indicates not detected. Heavy and dotted lines indicate the threshold value for arsenic skin lesions $(300 \mu \mathrm{g} / \mathrm{L}$; Chakraborti et al., 2003), and the Vietnam standard and WHO guidelines (10 $\mu \mathrm{g} / \mathrm{L}$; Ministry of Health of Vietnam, 2002; WHO, 2004), respectively. 

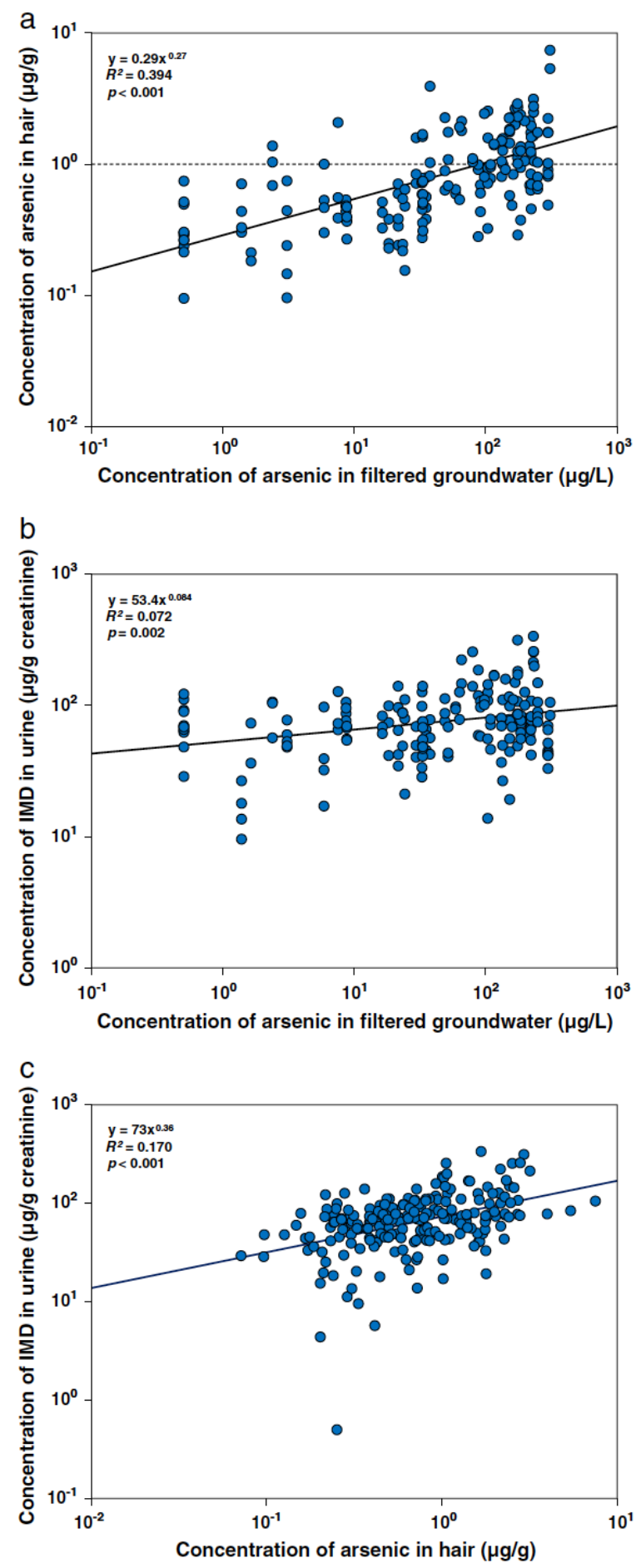

Fig. 3. Relationships between (a) concentrations of arsenic in sand-filtered water and human hair, (b) concentrations of arsenic in sand-filtered water and IMD in human urine, and (c) concentrations of arsenic in human hair and IMD in human urine from Dan Phuong, Ly Nhan, and Hoai Duc. The solid lines represent the regression lines. Dotted line in Fig. 3a indicates the threshold value for arsenic skin lesions ( $1 \mu \mathrm{g} / \mathrm{g}$; Chakraborti et al., 2003). Samples with concentrations of total arsenic and arsenic compounds below the detection limit are plotted as the value of detection limit. 

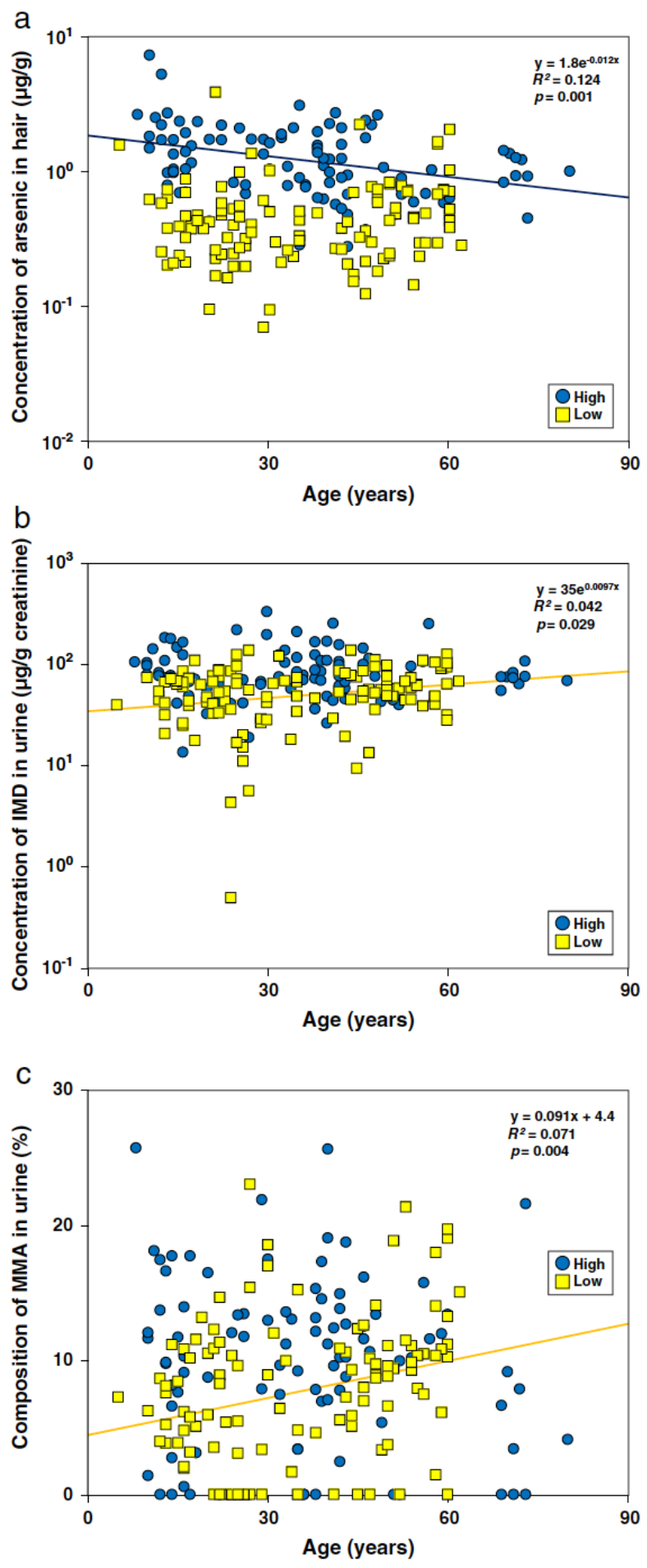

Fig. 4. Relationships between (a) age and arsenic concentration in human hair, (b) age and IMD concentration in human urine, and (c) age and composition of MMA in human urine from residents in Tu Liem, Dan Phuong, Ly Nhan, and Hoai Duc. Solid lines in Figs. 4a, and 4b and 4c are the regression lines of the high arsenic exposure (Fig. 4a) and low arsenic exposure groups (Figs. $4 \mathrm{~b}$ and c), respectively. Samples with concentrations of total arsenic and arsenic compounds below the detection limit are plotted as the value of detection limit. 